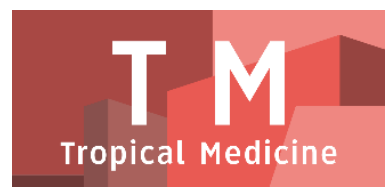

PAPER - OPEN ACCESS

\title{
Aktivitas Antelmintik Subfraksi dariFraksi Etanol Daun Pugun Tanoh [Picria fel-teraae (Lour.)]
}
Author
DOI
: Popi Patilaya
Electronic ISSN
: $10.32734 /$ tm.v1i3.272
Print ISSN
: 2623-0542
: 2623-0550

Volume 1 Issue 3 - 2018 TALENTA Conference Series: Tropical Medicine (TM)

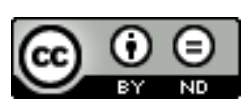

This work is licensed under a Creative Commons Attribution-NoDerivatives 4.0 International License.

Published under licence by TALENTA Publisher, Universitas Sumatera Utara
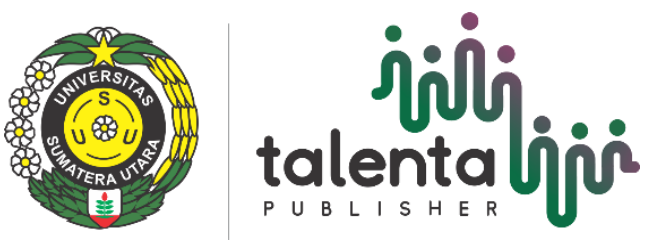


\title{
Aktivitas Antelmintik Subfraksi dariFraksi Etanol Daun Pugun Tanoh [Picria fel-teraae (Lour.)]
}

\author{
Popi Patilaya ${ }^{a^{*}}$, Dadang Irfan Husori ${ }^{\mathrm{b}}$, Henny Sri Wahyunic \\ ${ }^{a}$ Departemen Biologi Farmasi, Fakultas Farmasi, Universitas Sumatera Utara, Medan. \\ ${ }^{b}$ Departemen Farmakologi Farmasi, Fakultas Farmasi, Universitas Sumatera Utara. \\ ${ }^{c}$ Departemen Kimia Farmasi, Fakultas Farmasi, Universitas Sumatera Utara, Medan.
}

Email*: popi.patilaya@usu.ac.id

\begin{abstract}
Abstrak
Pugun tanoh [Picria fel-terrae (Lour.)] merupakan salah satu tumbuhan obat Indonesia yang memiliki potensi sebagai antelmintik. Ekstrak etanol daun pugun tanoh dan fraksi-fraksinya mampu membunuh cacing parasit Ascaris lumbricoides dan Ascaridia gali. Pengujian terhadap aktivitas antelmintik subfraksi dari ekstrak etanol tersebut perlu dilakukan sebagai upaya untuk memperoleh senyawa bioaktifnya. Penelitian ini bertujuan untuk mengetahui aktivitas antelmintik subfraksi dari fraksi etanol daun pugun tanoh. Penelitian dilakukan dengan memfraksinasi $20 \mathrm{~g}$ fraksi etanol daun pugun tanoh secara kromatografi cair vakum dengan fase gerak landaian n-heksana-etil asetat dan etil asetat-metanol menggunakan fase diam silika gel $60 \mathrm{H}$. Setiap $250 \mathrm{ml}$ cuplikan ditampung dan ditentukan pola kromatogramnya dengan kromatografi lapis tipis menggunakan fase gerak n-heksana-etilasetat (70:30) dan fase diam silika gel $\mathrm{GF}_{254}$. Cuplikan dengan pola kromatografi yang sama dikumpulkan sebagai satu subfraksi. Setelah diuapkan, subfraksi diuji aktivitas antelmintiknya terhadap Pheretima posthuma.Hasil penelitian menunjukkan bahwa fraksi etanol daun pugun tanoh menghasilkan 4 subfraksi yaitu SF1 (0,10\%), SF2 (4,00\%), SF3 (4,05\%), dan SF4 (73,55\%). Waktu kematian P. posthuma akibat paparan SF1, SF2, SF3, dan SF4 masing-masing adalah 77,00 $\pm 1,00$ menit; $56,33 \pm 1,76$ menit; 79,33 $\pm 1,33$ menit; dan 112,33 $\pm 0,67$ menit. Subfraksi dari fraksi etanol daun pugun tanoh memiliki aktivitas antelmintik dimana SF2 lebih kuat dibandingkan SF3, SF1, dan SF4.
\end{abstract}

Kata Kunci:Picria fel-terrae, pugun tanoh, antelmintik, helmintiasis.

\begin{abstract}
Picria fel-terrae (Lour.) is one of Indonesian medicinal plants which has potency as anthelmintic. Ethanol extract of this plant leaves and its fractions capable to kill both Ascaris lumbricoidesandAscaridia galiparasitic worms. Studies on the anthelmintic activity of subfractions from $P$. fel terrae ethanol extractarerequired as an attempt to obtain its bioactive compounds. This work was to study the anthelmintic activity of subfractions from ethanolic fraction of $P$. fel-terrae leaves. Study was performed by fractionating ethanolic fraction of $P$. fel-terrae leaves $(20 \mathrm{~g})$ with vacuum liquid chromatographyingradient mobile phases of n-hexane-ethyl acetate and ethyl acetate-methanolusing silica gel $60 \mathrm{H}$ as stationary phase. Each $250 \mathrm{ml}$ of aliquots were collected and its TLC pattern was determined on silica gel $\mathrm{GF}_{254 \mathrm{with}} \mathrm{n}$ hexane-ethylacetate(70:30, v/v) as mobile phase. The aliquots with the same TLC pattern was combined as a single subfraction. After evaporation, the anthelmintic activity of subfractions were tested on Pheretima posthuma.The results showed that ethanolic fraction of $P$. fel-terrae leaves produced 4 subfractions, namely SF1 (0.10\%), SF2 (4.00\%), SF3 (4.05\%), and SF4 (73.55\%). Time of death of P. posthumadue to exposure with SF1, SF2, SF3, and SF4 were recorded at $77.00 \pm 1.00$ minutes, $56.33 \pm 1.76$ minutes, $79.33 \pm 1.33$ minutes, and $112.33 \pm 0.67$ minutes, respectively. Subfractions from ethanolic fraction of $P$. fel-terrae leaves has anthelmintic activity where SF2 is more potent compared with SF3, SF1, and SF4.
\end{abstract}

Keywords: Picria fel-terrae, pugun tanoh, anthelmintic, helminthiasis.

\section{Pendahuluan}

Resistensi cacing parasit terhadap antelmintik merupakan permasalahan serius tidak hanya bagi kesehatan hewan, tetapi juga manusia. Meskipun antelmintik masih menjadi obat utama dalam menanggulangi helmintiasis, namun ketergantungan pada golongan obat ini dapat memicu resistensi secara berkelanjutan[1]. Sepanjang satu setengah dekade cacing parasit telah muncul sebagai organisme resisten terhadap benzimidazol, tetrahidropirimidin, imidazotiazol, lakton makrosiklis [2-4], ivermektindanmoksidektin[5], serta 
monepantel[6].Situasi ini menyebabkan pengobatan menjadilebihsulit[7] sehingga perlu mengembangkanantelmintikbaruterutama daritumbuh-tumbuhan [8].

Pugun tanoh [Picria fel-terrae (Lour.)] merupakan salah satu tumbuhan obat Indonesia yang memiliki potensi sebagai antelmintik. Ekstrak etanol daun pugun tanoh dan fraksi-fraksinya mampu membunuh cacing parasit. Namun senyawa aktifnya belum diketahui, sehingga penelitian lanjutan perlu dilakukan sebagai upaya untuk memperoleh senyawa aktifnya. Ekstrak etanol daun pugun tanoh mengandung flavonoid, saponin, tanin, glikosida, dan steroid [9-10].

\section{Bahan dan Metode}

\subsection{Bahan}

Bahan kimia yang digunakan dalam penelitian ini berkualitas pro analisis yang diperoleh dari Merck (Jerman), meliputi n-heksana, etilasetat, silika gel $60 \mathrm{H}$, plat silika gel $\mathrm{GF}_{254}$, natirum CMC, dan Tween-80. Pirantel baku diperoleh dari Sigma-Aldrich (Amerika serikat). Fraksi etanol dari ekstrak etanol daun pugun tanoh diperoleh dari peneliti sebelumnya (Popi Patilaya dkk.).

\subsection{Hewan Percobaan}

Cacing Pheretima posthuma dikumpulkan dari Kebun Fakultas Farmasi Universitas Sumatera Utara. Spesies diidentifikasi oleh Laboratorium Sistematika Hewan, Departemen Biologi, Fakultas Matematika dan Ilmu Pengetahuan Alam, Suniversitas Sumatera Utara Medan.

\subsection{Penyiapan Sub-fraksi}

Fraksi etanol dari ekstrak etanol daun pugun tanoh difraksinasi secara kromatografi cair vakum dengan fase gerak landaian n-heksana - etil asetat dan etil asetat - metanol dengan perbandingan (100:0), (90:10), (80:20), (70:30), (60:40), (50:50), (40:60), (30:70), (20:80), (10:90), (0:100), dan metanol mengunakan fase diam silika gel $60 \mathrm{H}$. Setiap $250 \mathrm{ml}$ cuplikan ditampung dan ditentukan pola kromatogramnya dengan kromatografi lapis tipis (KLT) menggunakan fase gerak n-heksana - etilasetat (70:30) dan fase diam silika gel GF $_{254}$. Cuplikan dengan pola kromatografi yang sama dikumpulkan sebagai satu subfraksi. Setelah diuapkan, subfraksi yang diperoleh dikemasdalambotolberwarnagelapdandisimpandalamlemaripendinginpadasuhu $4^{\circ} \mathrm{C}[11]$.

\subsection{Uji Aktivitas Antelmintik}

Uji aktivitas antelmintik dilakukan berdasarkan prosedur Agrahari et al. (2011)dan Hounzangbe-Adoteet al. (2005) denganmodifikasi minor. CacingPheretimaposthumadiaklimatisasidalamlarutansalinselama 60 menit [1213]. Hewan percobaan dipaparkan terhadap bahan uji yaitu sub-fraksi $0,1 \%$; pirantel $0,1 \%$; dan kontrol salin yang mengandung CMC 0,5\% dan Tween-80. Aktivitas antelmintik bahan uji ditentukan berdasarkan waktu paralisis dan kematian hewan percobaan.

\section{Hasil dan Pembahasan}

Hasil fraksinasi terhadap fraksi sisa dari ekstrak etanol daun pugun tanoh menghasilkan 4 sub-fraksi berdasarkan profil KLT-nya (Gambar 1), yaitu sub-fraksi 1 (bercak 1), sub-fraksi 2 (bercak 2 - 5), sub-fraksi 3 (bercak 6 -9), dan sub-fraksi 4 (bercak $11-21$ ). Persentase sub-fraksi yang diperoleh dapat dilihat pada Tabel 1 .

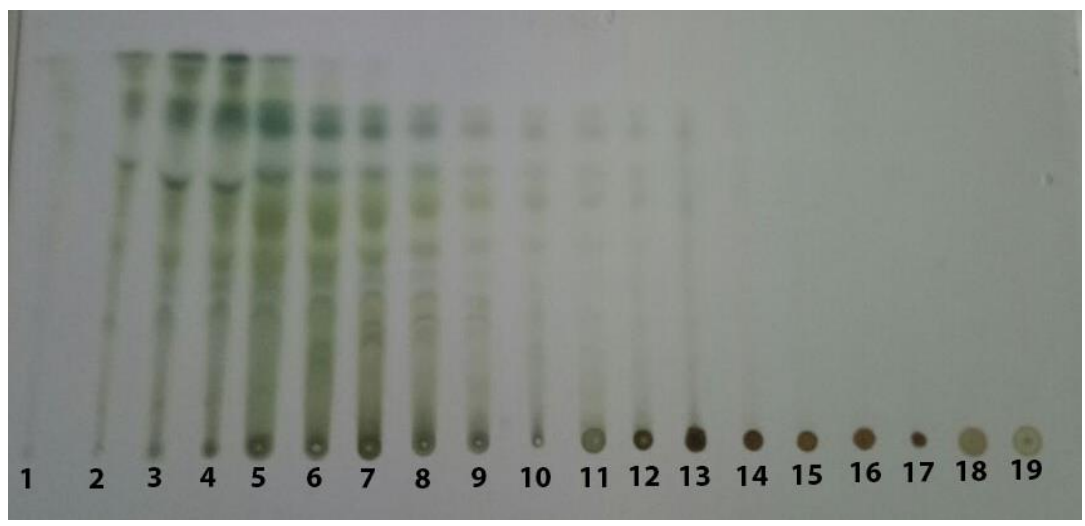

Gambar 1. Profil KLT subfraksi sisa dari ekstrak etanol daun pugun tanoh pada fase diam silika gel dan fase gerak n-heksana-etilasetat 7:3. 
Tabel 1. Jumlah Subfraksi dari $20 \mathrm{~g}$ Fraksi Sisa Daun Pugun Tanoh

\begin{tabular}{|c|c|c|c|}
\hline No. & Subfraksi & Berat $(\mathrm{g})$ & Persentase \\
\hline 1. & Subfraksi-1 & 0,02 & $0,10 \%$ \\
\hline 2. & Subfraksi-2 & 0,80 & $4,00 \%$ \\
\hline 3. & Subfraksi-3 & 0,81 & $4,05 \%$ \\
\hline 4. & Subfraksi-4 & 14,71 & $73,55 \%$ \\
\hline
\end{tabular}

Tabel 2 menyajikan aktivitas antelmintik sub-subfraksi dari fraksi etanol daun pugun tanoh. Hasil penelitian menunjukkan bahwa aktivitas antelmintik subfraksi-2 > subfraksi-3 dan subfraksi-1 > subfraksi-4 dan pirantel $0,1 \%$. Aktivitas antelmintik subfraksi-2 ini juga lebih kuat dibandingkan aktivitas antelmintik sub-subfraksi nheksana dari fraksi yang sama [14]. Maka subfraksi-2 perlu diteliti lebih lanjut untuk memperoleh senyawa aktif yang bertanggungjawab terhadap aktivitas antelmintik daun pugun tanoh. Disimpulkan bahwa subfraksi etanol dari fraksi etanol daun pugun tanoh memiliki aktivitas antelmintik terhadap P. Posthuma.

Tabel 2.Aktivitas antelmintik subfraksi dari fraksi etanol daun pugun tanoh terhadap Pheretima posthuma (Data disajikan sebagai rata-rata \pm

\begin{tabular}{clll}
\multicolumn{5}{c}{ galat baku) } & \\
\hline No. & Perlakuan & Waktu Paralisis* (menit) & Waktu Kematian* $(m e n i t)$ \\
\hline 1. & Subfraksi-1 & $77,00 \pm 1,00^{\mathrm{a}}$ & $119,00 \pm 2,31^{\mathrm{a}}$ \\
2. & Subfraksi-2 & $56,33 \pm 1,76^{\mathrm{b}}$ & $73,33 \pm 3,18^{\mathrm{b}}$ \\
3. & Subfraksi-3 & $79,33 \pm 1,33^{\mathrm{a}}$ & $121,00 \pm 2,08^{\mathrm{a}}$ \\
4. & Subfraksi-4 & $112,33 \pm 0,67^{\mathrm{c}}$ & $139,67 \pm 5,04^{\mathrm{c}}$ \\
5. & Pirantel 0,1\% & $127,33 \pm 1,45^{\mathrm{c}}$ & $140,00 \pm 2,65^{\mathrm{c}}$ \\
6. & Kontrol & $310,33 \pm 2,60^{\mathrm{d}}$ & $369,33 \pm 2,91^{\mathrm{d}}$ \\
\hline
\end{tabular}

*a, b, c, d adalah notasi uji statistika, nilai waktu kematian dan waktu paralisis dengan notasi yang sama artinya bahwa hasil uji statistika tidak menunjukkan perbedaan yang nyata, demikian juga sebaliknya.

\section{Ucapan Terima Kasih}

Penulis berterima kasih kepada Kementerian Riset, Teknologi dan Pendidikan Tinggi yang telah memberikan bantuan dana melalui skim Penelitian Dasar Unggulan Perguruan Tinggi tahun 2018 dengan nomor kontrak 10/UN5.2.3.1/PPM/KP-DRPM/2018.

\section{Daftar Pustaka}

[1] Prichard RK, von Samson-Himmelstjerna G, Blackhall WJ, Geary TG, 2007. Foreword: Towards markers for anthelmintic resistance in helminths of importance in animal and human health. Parasitology, 134, 1073-1076.

[2] Borgsteede FHM, Dercksen DD, Huijbers R, 2007. Doramectin and albendazol resistance in sheep in the Netherlands. VeterinaryParasitology, 144, 180-183.

[3] Sargison ND, Jackson F, Bartley, Moir ACP, 2005. Failure of moxidectin to control benzimidazole, levamisole and ivermectin resistant Teladorsagiacircumcincta in a sheep flock. Veterinary Record, 133, 445-447.

[4] Sargison ND, Scott PR, Jackson E, 2001. Multiple anthelmintic resistance in sheep. Veterinary Record, 149, $778-779$.

[5] Geurden T, van Doorn D, Claerebout E, Kooyman F, De Keersmaecker S, Vercruysse J, Besognet B, Vanimisetti B, Frangipane di Regalbono A, Beraldo P, Di Cesare A, Traversa D, 2014. Decreased strongyle egg re-appearance period after treatment with ivermectin and moxidectin in horses in Belgium, Italy and The Netherlands. VeterinaryParasitology, 204, $291-296$.

[6] van den Brom R, Moll L, Kappert C, VellemaP, 2015.Haemonchuscontortus resistance to monepantel in sheep. Veterinary Parasitology, 209, 278-280.

[7] Graef JD, Claerebout E, Geldhof P, 2013. Anthelmintic resistance of gastrointestinal cattle nematodes. VlaamsDiergeneeskundigTijdschrift. 82, 113-123.

[8] Yadav P, Singh R, 2011. A review on anthelmintic drugs and their future scope. International Journal of Pharmacy and Pharmaceutical Sciences, 3, 17-21.

[9] Patilaya P, Husori DI, Sumantri IB, 2017. The Anthelmintic Effects of Ethanol Extract of CurangaFel-terrae Leaves on Ascaridia Galli. Journal of Pharmaceutical and Clinical Research, 10, 117-119.

[10] Patilaya P, Husori DI, 2015. Preliminary study on the anthelmintic activity of the leaf ethanolic extract of Indonesian Curangafelterrae (Lour.) Merr. International Journal of PharmTech Research, 8, 347-351.

[11] Hostettmann K, Marston A, Hostettmann M, 1998. Preparative Chromatograpgy Techniques: Aplication in Natural Product Isolation. New York: Spinger-Verlag Berlin Heidelberg, p:39-41.

[12] Agrahari AK, Meher A,Padhan AR, Dash S, 2011. Assessment of anthelmintic activity of Jussiaeahyssopifolia G. Don. Asian Journal of Plant Science and Research, 1, 87-91.

[13] Hounzangbe-Adote S., Fouraste I., Moutairou K., Hoste H, 2005. In vitro effects of four tropical plants on the activity and development of the parasitic nematode, Trichostrongylus colubriformis. Journal of Helminthology, 70, 29-33.

[14] Patilaya P, Husori DI,Sumantri IB, 2017. Anthelmintic Activity of Subfractions from the n-hexane fraction of Picria fel-terrrae Leaves on Pheretima posthuma. $1^{\text {st }}$ International Conference on Pharmaceutical and Clinical Research. Faculty of Pharmacy, Universitas Sumatera Utara, 3 Nopember 2017. 